\title{
Transversalizar una perspectiva: voces, espacios y tiempos de la Educación Sexual Integral
}

\author{
(1) Catalina González del Cerro \\ Universidad de Buenos Aires, Argentina \\ catalinag@gmail.com
}

\begin{abstract}
Resumen
Este trabajo recoge aportes de mi investigación doctoral sobre la perspectiva de género en la escuela secundaria y en particular reúne algunas reflexiones en torno a la transversalidad. En primer lugar, reconstruyo algunos debates teóricos sobre este concepto a partir de hacer confluir las diversas definiciones que construyeron por separado la pedagogía, los estudios feministas y la normativa de la Educación Sexual Integral. En segundo lugar, retomo parte de mi trabajo etnográfico para describir algunas de las acciones llevadas adelante por un grupo de estudiantes y docentes de una escuela de la ciudad de Buenos Aires con el fin de sensibilizar a la comunidad en torno a las desigualdades de género. A partir de identificar tensiones en el uso de las voces, los espacios y los tiempos, propongo un esquema que busca tornar inteligibles los modos posibles en los que se despliega la enseñanza transversal de la perspectiva de la ESI en el contexto extra-áulico.
\end{abstract}

Palabras clave: Feminismos, juventudes, institución, validación, secundaria

\section{Transversalize a perspective: voices, spaces and times of Comprehensive Sex Education}

\begin{abstract}
This work gathers contributions from my doctoral research on the gender perspective in high school and in particular gathers some reflections on transversality. In the first place, I reconstruct some theoretical debates about this concept by bringing together the different definitions that built pedagogy, feminist studies and Comprehensive Sexual Education Law. I also analyze the actions carried out by a group of students and teachers of a school in the city of Buenos Aires in order to sensitize the community about gender inequalities. From identifying tensions in the use of voices, spaces and times, I propose a scheme that seeks to make intelligible the possible ways in which the transversal teaching of the ESI perspective unfolds outside the classroom.
\end{abstract}




\section{Introducción}

Los planteos que se despliegan a continuación responden a uno de los interrogantes que guiaron mi investigación doctoral y que considero central dentro de los estudios sobre la Educación Sexual Integral en la actualidad: ¿qué condiciones y estrategias institucionales habilitan o limitan su implementación? En la tesis titulada "Educación Sexual Integral, participación política y socialidad online: una etnografía sobre la transversalización de la perspectiva de género en una escuela secundaria de la Ciudad Autónoma de Buenos Aires", analicé los modos en que los "saberes de género" son seleccionados, producidos, validados y transmitidos en las instituciones educativas a partir de lo observado en una institución específica. Entre los años 2014 y 2017 observé y analicé el despliegue de acciones para la implementación de la ESI en una escuela secundaria, que de aquí en más denominaré "Escuela $\mathrm{P}$ ". Se trata de una institución de gestión estatal, ubicada en el centro de la Capital, con una antigüedad de más de 100 años y una población de aproximadamente 125 docentes y 1050 estudiantes pertenecientes a un sector socioeconómico medio-bajo. Una característica que para este trabajo resulta importante resaltar es que se trata de un colegio con un Centro de Estudiantes activo y una tradición de docentes con participación sindical, razón por la cual muchxs ${ }^{2}$ integrantes la denominan como una escuela "politiquera".

En ella pude observar un proceso de progresiva apropiación de la normativa ESI por parte de la mayoría de lxs estudiantes y docentes, que fue impulsada por una alianza política y pedagógica entre un agrupamiento de docentes autodenominado "Equipo de profes ESI" y estudiantes de la joven "Secretaría de Género" del Centro de Estudiantes. Ambos grupos se constituyeron como tal en forma casi simultánea poco antes de mi llegada y con la característica de haberse acompañado mutuamente en su consolidación al interior de sus claustros. Este colectivo intergeneracional, el que denominé "Grupo ESI-Género", fue creciendo en visibilidad dentro de la escuela durante el periodo del trabajo de campo. Sus diversas líneas de acciones estuvieron orientadas hacia modos particulares de promover un proceso de "politización de género" en la comunidad, por momentos bajo el explícito aval de la conducción y por momentos con algunos niveles de confrontación.

El equipo de docentes ESI y la Secretaría de Género comenzaron a confluir con mayor frecuencia a partir de 2015; comenzaron a juntarse en un espacio no pautado inicialmente por la institución, al que denominaron Aula ESI y que consistía en un espacio en desuso que otrora servía para talleres de ajedrez. Se reunían en un tiempo tampoco pautado por las autoridades: el horario de entreturno, es decir, al mediodía, cuando la mayoría de lxs interesadxs en participar de las reuniones tenía más disponibilidad. Dicho grupo interclaustro mantenía su propio grupo de WhatsApp y también interactuaban, con una frecuencia que fue solo inicial en un grupo cerrado de Facebook. En ambas plataformas también contaban con grupos intrageneracionales, entre estudiantes por un lado y entre docentes por el otro. Según una ponencia redactada por lxs "profesors ESI", conformado por unos seis docentes de distintas áreas curriculares (Lengua, Historia, Química, Psicología), las acciones del equipo involucraron tres "modalidades complementarias": el abordaje de los contenidos ESI en cada materia, el abordaje de los contenidos ESI en espacios curriculares específicos obligatorios y el abordaje de situaciones cotidianas, incidentales, disruptivas.

\footnotetext{
1 Se utilizará un nombre ficticio para resguardar a la identidad de la institución y sujetos analizados.

2 Hago uso de la flexión de género en “x” para la escritura en los casos en los que designo a lxs sujetxs. Si bien esta decisión no va a modificar ni desestabilizar las formas de subordinación propias de las relaciones sociales, considero que abona a contrastar críticamente el protocolo hegemónico de la construcción masculina del sujeto universal, y a visibilizar las relaciones de poder sexista que se expresan a través del lenguaje. Dado que no existe un consenso formulado desde los activismos y los estudios de género, opto por presentarla como una estrategia provisoria, como lo son también el uso de otras alternativas comola e, la l, el @, o el *.
} 


\section{Las formas de lo transversal}

Con el fin de complejizar estas "modalidades", a continuación desarrollaré brevemente las aproximaciones sobre la noción de transversalidad desde tres campos que confluyen en mi objeto de investigación y que pocas veces aparecen dialogando en los estudios sobre la ESI: el de la pedagogía, el de los feminismos y el del lenguaje estatal del propio Programa Nacional ESI. Si nos enfocamos en los debates propios de la pedagogía podemos ubicar los "contenidos transversales" como parte de un debate que se instala a partir de los años ' 90 de la mano de las reformas curriculares promovidas por organismos internacionales. En un primer momento generaron gran entusiasmo en diferentes latitudes, pero luego no se tradujeron a modificaciones sustantivas en las estructuras del sistema educativo. Dice Isabelino Siede que estos grandes campos de problemas/contenidos, tales como la educación para la paz, la ambiental, de derechos humanos, involucran "una visión totalizadora en la que nada de lo que ocurra en el escenario educativo pueda quedar por fuera" (1998: 169). En un trabajo mucho más reciente, la especialista en currículum Alicia de Alba señala que los contenidos transversales nos remiten a una complejidad que golpea constantemente a la cultura, y que los mismos permiten analizar la relación entre currículum y un contexto actual que describe como de "tensión globalizacióncrisis estructural generalizada, que implica desconcierto, falta de timón" (2015: 207). Para ambxs autorxs, los temas transversales tienen la función, además de direccionar la enseñanza, de involucrar a todxs los sectores de una comunidad y explicitar aquello que una sociedad en un momento dado considera como valores fundamentales.

En la literatura más próxima a los feminismos, transversal deviene del término anglosajón mainstreaming (Bach,2015) y refiere a un proceso o instrumento estratégico -y no un fin en sí mismo- para alcanzar la igualdad, en este caso específicamente de género; se trata de un instrumento que organiza el soporte, la ejecución y la evaluación de las políticas de género. Destaco aquí esta marca en el origen de la expresión perspectiva de género asociada a su carácter inherentemente transversal que contiene en sí mismo una responsabilización por parte de todxs lxs actores, especialmente a lxs que ocupan espacios jerárquicos y que tiene su origen también en las directrices de organismos internacionales. En forma más reciente y en sintonía con los procesos de masificación de las demandas del movimiento de mujeres latinoamericanas, se ha denominado "feminismos transversales" a los procesos de construcción de redes territoriales que ha puesto el foco en el encuentro con otras luchas de actores sociales heterogéneos (Gago, 2019). Si bien son innumerables las categorizaciones de los feminismos actuales -populares, juveniles, digitales, transfeminismos- que no llegaré a desarrollar aquí, considero que estas genealogías trenzadas derivan de una dinámica basada en una capacidad de reflexividad de sus prácticas y una actualización constante de sus premisas a partir de revisarse en situaciones "cotidianas, incidentales, disruptivas". Como desarrollé más extensamente en la tesis, estas formas de acción feminista entrenadas en desplegar redes capilares, simultáneas y heterogéneas se están traduciendo en las formas en que lxs jóvenes se aproximan a la política en general y a la estudiantil en particular durante la última década.

En el cruce de ambas líneas encontramos los desarrollos de la pedagogía feminista y queer (Maher y Thompson; 1994; Mcintosh, 1997; Subirats y Brullets, 1988; Lopes Louro, 1999). Para esta corriente, que ha sido poco explorada como tal a nivel local y académico, la inclusión de la perspectiva de género o feminista requiere necesariamente cuestionar la jerarquía de los saberes enseñados, reconfigurar el vínculo pedagógico, considerar el valor epistémico de la confianza, la experiencia y las emociones, entre varios asuntos más. Si bien estos desarrollos son fundamentales para comprender en profundidad los derroteros posibles a los que se enfrenta la perspectiva de género en todos los ámbitos de enseñanza, resulta necesario situar estas reflexiones en el contexto de las escuelas secundarias de la CABA; requieren ser revisados a la luz de las 
coyunturas y las disposiciones gubernamentales locales. Y esto nos lleva a la tercera línea: ¿Qué mejor que la transversalidad de la ESI en la escuela para pensar este feminismo transversal latinoamericano que se piensa incompleto y desde allí establece alianzas interterritoriales, interdisciplinares e intergeneracionales?

La transversalidad presente en los documentos de la ESI se sustenta en la prerrogativa de la normativa de que las escuelas deben considerar la sexualidad integral como contenido presente en todas las asignaturas. Según se deja ver en los lineamientos curriculares nacionales de la ESI, la decisión de que las escuelas secundarias incorporen un abordaje "transversal y/o en espacios específicos" se debe a la necesidad de transformar una práctica usual que sostenía, a veces de forma implícita y desregulada, que quienes más sabían sobre sexualidad eran lxs docentes de ciencias naturales o invitadxs del ámbito de la salud. Este desplazamiento que trae la ESI requiere, en la práctica, que todas las asignaturas se dispongan a revisar los cruces entre sus saberes disciplinares y los saberes del campo de estudios de sexualidad, género y derechos humanos. Vale destacar que dicho diálogo disciplinar estuvo y está escasamente desarrollado en la mayoría de las carreras de base e instituciones de formación docente. A su vez, las instituciones escolares pasan a enfrentarse con una ambigüedad desafiante: es la que debe generar sus propios dispositivos de selección, validación y transmisión de esos saberes interdisciplinarios. Y el Ministerio de Educación, en particular el Programa ESI y sus variantes provinciales, se torna fuente de insumos centrales para establecer el piso de saberes obligatorios y el techo de los saberes legítimos.

Entre los obstáculos que suelen destacarse con relación a la implementación de la ESI, se encuentran aquellos que rápidamente la asocian con tensiones de índole ideológica y política, algo que sin duda persiste en muchas escuelas. Pero aquí quisiera enfocarme en uno poco explorado: las limitaciones del propio dispositivo escolar. En los años siguientes a la sanción de la ley, algunas comunidades escolares que manifestaban compromiso con el enfoque de la ESI comenzaron a identificar distintas dificultades para llevarla a la práctica. Frente a esto, lxs responsables del Programa Nacional de ESI publicaron la "Guía para el desarrollo institucional de la Educación Sexual Integral", en la cual se señala que "la educación sexual atraviesa nuestra práctica docente a toda hora y en todo lugar" (2012: 7). Es aquí donde se desarrolló uno de los esquemas más significativos que caracterizan a esta política: los cinco ejes transversales ${ }^{4}$ y las "puertas de entrada de la ESI". En este esquema de puertas se destaca una mayor complejización de la noción de transversalidad a partir de incorporar, entre otras formas posibles de implementación de la ESI, la organización de la vida cotidiana institucional como ocupando un rol central en los proceso de enseñanza y aprendizaje sobre la sexualidad integral.

Ahora bien, considero que estos esquemas no profundizan en traducir y reconocer, de forma más masiva e intencionada, los aportes de las pedagogías feministas. En particular en lo que atañe a la necesidad de un verdadero quiebre epistemológico ante los saberes tradicionalmente androcéntricos y una revisión profunda sobre las formas en que estos "otros saberes" de las voces feministas se incorporan a la enseñanza. Aquí retomo como herramienta conceptual lo que la pedagoga argentina Flavia Terigi (2008) denomina "el trípode de hierro" de las escuelas secundarias. Este trípode, que se sostiene

\footnotetext{
3 "En el caso del enfoque transversal, se propenderá a que su adopción garantice el tratamiento de la ESI en forma continua, sistemática e interdisciplinaria, evitando que se diluyan los contenidos pertinentes y sus propósitos formativos. En caso de que se defina el tratamiento de la ESI en el marco de un espacio curricular específico, el abordaje deberá ser integral para evitar reduccionismos que podrían empobrecer el enfoque interdisciplinario que aquí se sustenta" ( Lineamientos curriculares para la ESI, CFE 2008, p.16).

4 Es en el año 2018 cuando estos ejes toman jerarquía a partir de la Resolución del CFE № 340/18, en la cual se esgrime: "Con el objeto de dar efectivo cumplimiento a la Ley N²6.150 de Educación Sexual Integral y garantizar el desarrollo de los lineamientos curriculares, las jurisdicciones se comprometen a implementar la obligatoriedad de la educación sexual integral en todos los niveles y modalidades educativas, abordando, sin excepción, los cinco ejes conceptuales: Cuidar el cuerpo y la salud. Valorar la afectividad. Garantizar la equidad de género. Respetar la diversidad. Ejercer nuestros derechos".
} 
en la estabilidad curricular, la composición de la planta docente y la organización de los horarios de trabajo de lxs profesorxs, conforma una base material que condiciona fuertemente el éxito o fracaso de las reformas educativas.

Guiada bajo este interrogante sobre las condiciones y las estrategias posibles, en mi trabajo etnográfico describí lo vivido en la Escuela $\mathrm{P}$ en un contexto y periodo marcado, entre otros indicadores, por las transformaciones que experimentó la población juvenil porteña antes, durante y después de la primera movilización convocada por "Ni una Menos" el 3 de junio de 2015. Durante mis visitas a esta escuela, pude acompañar las reflexiones y acciones colectivas vinculadas a situaciones cotidianas que involucraban a gran parte de los actores de la comunidad. Esto me llevó a ahondar en las formas en que se involucraban vínculos y saberes que trascendían la órbita docente y que aparecían desdibujados en los documentos oficiales de la ESI. Tal es el caso de la omisión de lxs estudiantes como potenciales protagonistas en la promulgación de la ESI. Lxs jóvenes resultaron ser -en esta y en muchísimas otras escuelas- aquellxs actores inesperadxs y aliadxs estratégicos para lxs docentes; aquellxs que tensionaron con mayor fervor los sentidos disputados sobre la educación sexual a la vez que la transformaron en un derecho estudiantil.

A partir de encuentros que excedían los programados por la distribución de áreas curriculares, el grupo ESI-Género buscó alterar la cotidianeidad de la institución a partir de planificar lo que aquí denomino "disrupciones institucionales": a) instituyó como autorizadas las voces de los movimientos sociales, lxs docentes y lxs estudiantes; b) se apropió de espacios del establecimiento que fueron identificados como superficies posibles de ser intervenidas y resignificadas, c) engrosó la efemérides estudiantil al incorporar fechas relevantes para la lucha del movimiento de mujeres y LGTBI. Son tres aspectos que remiten a un corrimiento de los márgenes de lo decible, visible y audible dentro del edificio escolar, y que tensionan los mapas de validación de los saberes en la vida cotidiana de la institución.

\section{a. Las voces: otrxs especialistas}

Uno de los mayores quiebres conceptuales que trajo la ESI fue establecer un corrimiento en los criterios de idoneidad para habilitar una pregunta aún compleja de responder: ¿Quién/es sabe/n sobre sexualidad? Revisar la posición epistémica en relación con la autoridad social forma parte de una reflexividad en torno a un problema de fondo con el que insiste Terigi (2013). Si bien la autora no se refiere específicamente al campo de la ESI, establece un puente clave con la pedagogía feminista al enunciar el siguiente problema: "La escuela transmite un saber que no produce; $y$ para poder llevar adelante ese trabajo de transmisión, produce un saber que no es reconocido como tal" (2013: 99). Ello configura un problema para la legitimidad del trabajo docente; problema que es nodal para abordar una política que plantea una responsabilización de todxs lxs directivxs y docentes en formarse en aspectos que no solo les resultan ajenos a su "saber sabio"; tampoco cuentan con el ejercicio de autolegitimar los saberes producidos en su práctica diaria.

Si retomamos lo observado en la Escuela P, lo que sucedió fue un proceso de legitimación por parte de la escuela de los saberes producidos por el grupo ESI-Género. Por un lado, se autorizó a lxs profesores por su esfuerzo continuo, su sistematicidad en registrar las actividades y porque, en palabras de la asesora pedagógica, "tienen formación de afuera, más ideología política, lo que hace un combo interesante y movilizante". Asimismo, observé que en testimonios o gestos de otrxs docentes que no formaban parte del equipo ESI se percibía cierta inseguridad frente al vocabulario "ultraespecializado" de los estudios de género y/o frente a la desactualización de lo que se considera políticamente correcto en ámbitos de discusión académicos y activistas. Tanto lxs docentes ESI como lxs estudiantes del grupo reconocían esta validación -y los conflictos con sus pares que por momentos traía- y a su vez en sus testimonios se autovalidaban con un "otro" saber o perspectiva que consideraban que en la escuela 
(y en la sociedad) no circulaba lo suficiente. Aquí quisiera detenerme en una de las fuentes de saber principales - pero no únicas- que estxs sujetos constituyeron como legítima para abordar la ESI con perspectiva de género. Me refiero a las organizaciones feministas y activistas LGTBI que lxs integrantes del grupo ESI-Género conocían y tenían acceso para contactar. Se constituyeron en fuentes de referencia y de validación de diversos debates y materiales, muchos de ellos de circulación online.

Las jornadas con invitadxs llevadas a cabo entre 2015 y 2017 incluyeron a una activistaartista que tenía una agrupación contra la violencia de género, un grupo de personas gays, lesbianas, varones y mujeres trans que en su mayoría pertenecían a alguna agrupación de activismo LGTBI, la reconocida activista y artista trans Susy Shock, un grupo de personas que militaban por la despenalización del aborto, un joven egresado gay de la escuela, entre otras. También se establecieron contactos con feministas que militaban a favor del trabajo sexual y a otras que se oponían, pero esa charla no llegó a realizarse por razones organizativas. En general estxs activistas eran convocadxs por algunx miembrx del grupo ESI-género que lxs proponía en alguna reunión y que lxs conocían, o por "tenerlos de contacto en Facebook", o por la red de conocidxs cercanos a sus propias agrupaciones o círculos de amistad.

Si bien cada charla mantuvo sus particularidades propias dadas las disposiciones institucionales, la confluencia de invitadxs, los modos y tiempos de exposición, encontré que en general había una orientación común de lxs invitadxs a sensibilizar a partir de relatos testimoniales individuales enlazados con datos estadísticos, y a la vez expresaban posicionamientos frente a políticas estatales o a casos de coyuntura. Esta apelación a la propia experiencia o a situaciones de sufrimiento cotidiano es muy propia de las formas en que lxs colectivxs feministas fundamentan sus acciones y reclamos. Se trata también de voces y experiencias que han sido históricamente devaluadas y/o han sido otrxs lxs que han hablado por ellxs (médicxs o psiquiatras, o medios de comunicación, por ejemplo) razón por la cual la puesta en escena pública de aquello silenciado representaba un acto reivindicativo en sí mismo.

En algunxs casos, lxs invitadxs trajeron videos de sensibilización, powerpoints en los que mostraban algunas leyes o imágenes, que eran usadas como soportes o disparadores, a veces sin un orden secuencial claro. En general la charla era introducida y cerrada por algún docente o estudiante del grupo ESI-Género. En la mayoría de los casos se trató de generar una conversación con una sala llena de estudiantes, cuyas preguntas tendían a indagar en "lo que te dijeron tus papás", "¿cómo te sentiste cuando te diste cuenta que eras lesbiana?...", por poner ejemplos. También, estos debates fueron escenarios de algunos relatos por parte de estudiantes y docentes. En la mayoría de las que siguieron lxs invitadxs nombraron a la ESI como "algo que [ustedes lxs estudiantes] tienen que valorar". Emitieron comentarios como "yo cuando iba al colegio hubiese dado cualquier cosa por tener estos espacios", "yo veo que ustedes acá tienen profes de educación sexual con quien hablar".

Entonces, dos cuestiones se abren aquí. En primer lugar, la tendencia a citar como fuente de autoridad a personas reconocidas por sus experiencias militantes quiebra con los modos tradicionales de validación basados en especialistas que podían acreditar saberes médico-científicos. Sin embargo, la falta de títulos no significaba que estxs activistas (muchxs de ellxs profesionales de distintos campos) no contaran con saberes rigurosos sobre las causas que militaban, ya que de hecho solían desarrollar, como en el caso del aborto, una extensa argumentación para enfrentar la criminalización social predominante. En segundo lugar, reaparece la pregunta por los aspectos pedagógicos: se trata de "lxs nuevxs especialistas" externxs a la escuela, que vienen y se van, y que muchas veces no tienen formación pedagógica o el registro o vocabulario adecuado como para afrontar una sala llena de jóvenes de distintas edades e intereses. Morgade advertía en 2011 que por momentos lxs invitados en calidad de militantes "tienden a 
enfatizar la dimensión del empoderamiento o de la afirmación de la autoestima y solo aluden a una dimensión afectiva al trabajar sobre las situaciones de discriminación" (2011: 61). Lo que advierte la autora es la necesidad de potenciar una enseñanza que también habilite una dimensión de lo afectivo en términos de experiencias colectivas positivas, corporales y vividas desde el deseo y el placer.

\section{b. Los espacios: otras superficies}

Dicen Nuñez y Litichever que en los últimos años emergieron prácticas políticas estudiantiles que, si bien expresaron diversos reclamos, "rebasaron el espacio escolar y, a través de esa operación, simultáneamente reconfiguraron el espacio público al tornarse visibles más allá de la escuela. Una suerte de reencantamiento con lo público" (2015: 148). Este rebasamiento, reconfiguración y reencantamiento con el espacio público, tal como señala Aguilera (2011) para el caso de los pingüinos en Chile, se torna más evidente en la medida de fuerza utilizada con frecuencia para hacer oír sus reclamos, que es la toma material del edificio. Lo que me interesa retomar aquí es la utilización que hacen lxs jóvenes de estos espacios públicos, junto con sus docentes, con el fin de llevar adelante el objetivo de "concientizar sobre el machismo".

En la escuela observada era usual la elaboración de murales o afiches tanto para proyectos institucionales, de alguna asignatura o del propio Centro de Estudiantes. Muchas de estas expresiones reflejaban un tipo de discurso persuasivo como los que se utilizan para las campañas de bien público, por ejemplo sobre salud o cuidado del medio ambiente. Destaco esto porque parecía existir una suerte de cultura visual escolar en la que todo muro, tacho de basura o ventana era susceptible de convertirse en cartelera. Es así que incorporar la perspectiva de género en la Escuela P implicó teñir sus superficies, invadirla por todos los frentes, llenar de presentes violetas y verdes los pasillos centenarios. A diferencia de los procesos de enseñanza secuenciados y enmarcados en una organización espacio-temporal del aula, las acciones colectivas apelaban a los lenguajes de la identificación emotiva. En ellas confluían las técnicas desarrolladas por un registro comunicacional marketinero que también resultó apropiable por los activismos feministas, en particular aquellos que se sirvieron de las performances, la irrupción sorpresiva, la exposición creativa de los cuerpos, entre otras, con el fin de conmover públicos heterogéneos.

Si volvemos a los saberes de referencia activistas que mencionábamos antes, aparece aquí una continuidad entre imágenes, pintadas o pegatinas y los memes de circulación en sitios de redes sociales. Tanto adultos como jóvenes des-digitalizaban a través de impresiones o reproducciones artísticas textualidades provenientes de espacios online y offline. Un caso paradigmático fue toda la iconoclasia virtual que despertó la primera movilización "Ni una Menos" y que, por ejemplo, empapeló los armarios de la sala de profesores. Otro ejemplo fue la elaboración de figuras en el patio utilizando los papeles callejeros con anuncios de servicios sexuales, algo que fue copiado de performances de activistas locales que apelaban a denunciar la trata de mujeres.

En las escaleras hubo una serie de intervenciones, una con los nombres de mujeres asesinadas en cada escalón de la escalera de entrada a la escuela. En otra ocasión se utilizó la narración secuencial de los escalones: en cada peldaño, se escribieron palabras como desvalorizar, humillar, gritar, y otras que aumentaban en nivel de agresión en cada paso, hasta llegar al final donde esperaba un afiche recortado con forma humana que decía: ¿Dónde nace un femicidio? Como suele suceder con las intervenciones en espacios compartidos, estas no estaban exentas de conflictos. Un hecho a destacar es que esta intervención fue quitada al día siguiente por el personal de maestranza. Si bien luego pidieron disculpas, se generó allí una tensión no menor, que daba cuenta de un malestar de estxs no docentes frente a tales acciones. Parece confuso para el equipo comprender si estas limpiezas se deben a un malestar por el trabajo de más que les implicaba, o por no acordar con los contenidos. 
La apropiación espacial debe entenderse en primer lugar en relación con una de las características de esta escuela que es la disponibilidad de espacios con nulo o escaso uso, dada la historia de su edificación. La transformación del "Aula ESI" es un caso paradigmático que refleja cómo estas condiciones edilicias se conjugaron con una necesidad del grupo ESI-Género de institucionalizar su identidad como tal. Sucedió en una ocasión, durante 2015, que una de las docentes ESI solicitó las llaves de esta aula semivacía en la Secretaría de la escuela, y desde entonces comenzaron a repetir allí las reuniones, primero entre docentes del equipo ESI y luego con lxs estudiantes. Paulatinamente, fueron llenando de elementos que consignaban su especificidad, como un cartel en la puerta que decía Aula ESI y debajo los nombres de lxs seis docentes referentes. La puerta había sido pintada por lxs estudiantes con los colores de la bandera arcoiris el día que la elaboraron para llevarla a una marcha del orgullo.

Asimismo, también se recurrió a un espacio virtual: en un primer momento al grupo cerrado de Facebook denominado Género Colegio P. Si bien había sido creado por la Secretaría de Género del Centro de Estudiantes en 2014, luego se sumaron lxs docentes de equipo ESI, quienes a su vez compartían otro grupo específico de docentes. En un segundo momento, a mediados de 2016, crearon un grupo de WhatsApp con el mismo nombre, Género Colegio P. En estos grupos se solían compartir notas de actualidad, eventos, videos o sucesos en la escuela. En general lxs docentes que más comentaban eran lxs que también participaban activamente de las actividades y que eran a su vez quienes daban clases casi diariamente en la escuela. En el Whatsapp la frecuencia de intervenciones de parte de estudiantes y docentes era prácticamente equivalente.

Otra particularidad es la intervención de los bustos de la escuela. En diversos eventos lxs estudiantes jugaban con ponerles anteojos, carteles, y hasta en una ocasión se llenó de mariposas al prócer que da nombre a la escuela, en honor a las Mariposas Mirabal un 25 de noviembre, fecha que las homenajea en el Día internacional contra la violencia a las mujeres. Otra acción paradigmática es la utilización de pañuelos en los bustos, algo que expongo en las imágenes que siguen.
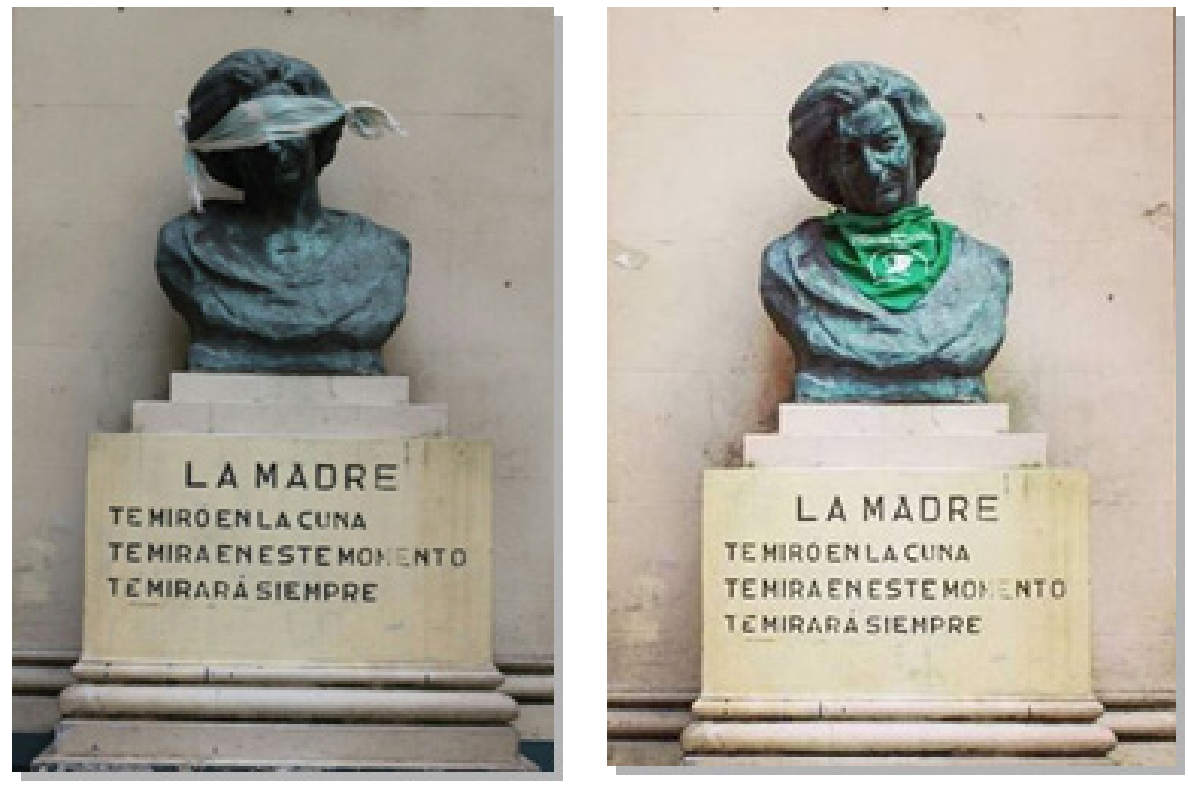

Figura 1. Fotografías tomadas por la misma profesora del equipo ESI, la primera en 2015 y la segunda en 2016 
En la Figura 1, vemos a la izquierda una intervención realizada para un 24 de marzo en el que se tapó con pañuelos blancos los ojos de todos los bustos de la escuela en alusión a la memoria por lxs 30.000 desaparecidxs, varones y mujeres vendadxs y torturadxs en la última dictadura militar. Para entonces, estudiantes y docentes elaboraron una bandera de gran tamaño que decía "Eran 30.000. Fue genocidio". En la imagen de la derecha se ve, un año después, el mismo busto que preside el patio central, la madre, colocada allí desde la construcción del edificio centenario, con un pañuelo de la Campaña Nacional por el Derecho al Aborto Legal Seguro y Gratuito. Es de destacar que de los más de cinco bustos distribuidos en toda la escuela, este es el único que representa a una mujer y no refiere a ningún personaje histórico particular (como sí lo hacen los otros bustos) sino que representa a un arquetipo de mujer anónimo, inseparable de la función social materna. En la semana en la que se realizó la charla sobre la interrupción del embarazo, con invitadas de "La Campaña por el derecho al Aborto Legal Seguro y Gratuito", también se elaboraron carteles con frases como " $L$ Los varones abortan cada vez que no se hacen cargo de sus hijxs?"; "Libertad para Belén5", y se colocó el pañuelo verde que es ícono de la lucha de "La Campaña". Es notable la resignificación de ambas acciones en dos sentidos: la ceguera de la madre que mira en la primera y la reivindicación de una madre que pregona por el derecho a decidir si serlo, en la segunda.

En cuanto a la utilización de los cuerpos en el espacio escolar, hubo en tres ocasiones intervenciones en alusión a la violencia hacia las mujeres. Estas implicaron diferentes posiciones, pero en general se recurrió a la puesta en escena de los cuerpos. Estas fueron: performance de chicas sentadas en las escalinatas centrales de la escuela vestidas de negro y con palabras humillantes o insultos escritos en su piel; performance de una chica recostada en la vereda de la escuela, con una bolsa que envolvía su cabeza, simulando estar muerta; performance de mujeres en la vereda que se habían pintado las palmas de las manos de rojo y se habían escrito "Basta" mientras miraban fijo a los ojos de lxs transeúntes con la mano extendida, en posición de detenerlxs. Por último, resalto una escena que se desarrolló en el hall de entrada, esta vez con cuerpos de varones. La acción la denominaron "el peso de los mandatos" y tenía la intención de interrumpir el flujo de cuerpos de estudiantes y docentes que entraban y salían de la escuela. Se trataba de una serie de cajas de cartones pintadas de negro que tenían escrito en cada lado mandatos sobre la masculinidad: "la poesía es para maricones", "poné huevo", "hacete hombre", "¿todavía no te la cogiste?" y varios más. Las cajas estaban depositadas en la mesa ovalada del medio del hall, y los varones que lo habían organizado pasaban a buscar algunas y se las amontonaban sobre los hombros, y allí quedaban sentados o parados cabizbajos. La escuela se convierte, así, en un lugar de interesante experimentación sobre los límites de lo posible para estxs jóvenes que se permiten aprender sobre los mandatos de género a partir de otros lenguajes y de la mano de otrxs desconocidxs, y principalmente en espacios públicos pero protegidos como puede ser su propia escuela. Se muestra aquí otra forma de enseñar a partir del poner el cuerpo, tal como pregonan muchas teóricas de la pedagogía feminista.

\section{c. Los tiempos: otras efemérides}

El establecimiento de un marco temporal, expresado en el tiempo del calendario escolar, es también la institución de relaciones de poder ejercido de manera visible o tácita (Escolano Benito, 2000). De allí que quienes logran mayor incidencia en la organización de los tiempos designados a cada asignatura, así como en la definición de qué se conmemora y de qué manera, hasta los tiempos destinados a cada actividad y las

5 Belén era el nombre ficticio de una jóven tucumana que en 2014 fue apresada luego de haber acudido a urgencias de un hospital público por una grave hemorragia vaginal y fue acusada por el médico de haberse "deshecho del feto" en uno de los baños del hospital, algo que ella negó. Fue liberada casi tres años después tras un fuerte repudio de organismos y de agrupaciones feministas. 
disrupciones a ese orden implican una disputa de poder. Tal como señala Willis (1983), tan importante como el edificio escolar tiene el plan de estudios como institución reguladora del tiempo. Es así que el equipo ESI-Género disputó -también- la arena política en torno a los usos del tiempo.

Para comenzar el análisis de la disputa temporal, retomo una escena que sucedió durante una de las actividades curriculares promovidas por la docente Viviana, en la que un curso de 5to año realizó un video sobre ESI como parte de un proyecto de la materia de Lengua y Literatura. En el video, una de las estudiantes mencionó, cuando se autoentrevistó, que uno de los contenidos que ella consideraba que se trabaja en la ESI eran las "fechas patrias de la mujer". Es posible que esta expresión elocuente la remita a la experiencia que vivieron ella y su curso ese año, en la que la profesora propuso profundizar en las razones que establecieron al 25 de noviembre como "Día internacional contra la violencia hacia las mujeres". Para entonces esta definición de la alumna nos pareció con Viviana algo muy cómico y generó algunas sonrisas a partir del error de la estudiante. Con el tiempo fue resultando evidente que esta identificación tiene sentido, ya que para lxs estudiantes estas fechas de la mujer fueron efectivamente trabajadas en la escuela con el mismo o mayor nivel de intensidad que las otras fechas patrias.

En la escuela, los días del calendario son ordenadores centrales que jerarquizan aquello que la escuela -y la patria- considera que ameritan una conmemoración. Tienen principalmente una función instrumental: detener el fluir del tiempo cotidiano y ritualizar un ejercicio de memoria y profundización. Manuel Castells (2002) utiliza el concepto de tiempo temporal para denominar a ese fenómeno que considera característico de esta sociedad de la información, en la que el tiempo se comprime y las cosas suceden en simultáneo. Frente a esta simultaneidad que por momentos agobia, el ordenamiento del tiempo tiene con más razón un sentido instrumental, sea en grillas que ordenan los horarios escolares o en un calendario que organiza los días importantes del año.

Las efemérides tienen también una función política: producir sentido en base a una historia en común. Toda conmemoración implica una revisión del pasado en la que este se construye como tradición que debe ser preservada; garantizan al sujeto un origen, un relato, un punto de apoyo para la construcción de sus propios discursos (Fattore, 2007). Al perpetuar el recuerdo sobre un hecho considerado trascendente, y que merece ser transmitido, lo inscriben dentro de una comunidad, a la que le permite sentir que pertenece. Los actos escolares, al intentar crear conexiones emocionales entre los participantes, producen un estado de comunidad y una forma de organizar los cuerpos en el espacio (Dussel y Southwell, 2009).

Los movimientos feministas y de disidencia sexual se han ocupado, a lo largo de las décadas, de establecer en encuentros internacionales y locales una serie de conmemoraciones a lo largo del año que sirven como motores de acciones de visibilización. Algunas son de larga data, como el 8 de marzo, muchas veces disputado con un mercado que lo utiliza para enfatizar algunas marcas estereotipadas de lo femenino, pero que los feminismos populares han enfatizado en señalar que se trata del Día internacional de las mujeres trabajadoras. El 17 de mayo, Día internacional contra la homofobia, la transfobia y la bifobia, es desde 2007 parte del calendario escolar de la CABA, algo considerado como una conquista de colectivos de disidencia sexual pero que aún en muchas escuelas se lo sigue ignorando.

Sucede también que esta agenda, sobre todo la internacional, no se acomoda fácilmente a los tiempos del calendario escolar local. Principios de marzo y fines de noviembre son momentos casi imposibles en cuanto a la cantidad de tareas implicadas en el inicio y cierre del año lectivo. Otras fechas de la agenda de género que podrían considerarse patrias, es decir nacionales, que han tomado relevancia en la escuela son, por ejemplo, 
el 3 de junio, como día que posiblemente ya haya quedado fijado como conmemoración de la primera movilización masiva "Ni una Menos" que tuvo lugar en 2015. También la marcha del orgullo que se realiza entre octubre y noviembre. Estas conmemoraciones pueden ser -y de hecho lo fueron en la escuela- instancias del año en que lxs jóvenes le presentan mayor atención a lo que se reivindica. Momentos en que los medios y los sitios de redes se hacen eco de estos eventos.

Retomo las efemérides de género ya que para el grupo ESI-Género representó un modo de organizar a largo plazo algunas actividades, tal como sucede por ejemplo con otras fechas patrias de la militancia estudiantil, como son el 16 de septiembre y el 24 de marzo. También cercana a estas fechas de la mujer suelen circular con mayor frecuencia contenidos digitales que remiten a ellas y dispone a lxs adultxs a acceder a insumos para trabajar el tema en sus asignaturas. El cruce entre la efemérides clásica escolar con los calendarios activistas genera, para aquellxs que consideran relevantes conmemorar estas fechas, una legitimación y una oportunidad para organizar esta inclusión de los saberes de género y abordarlos en profundidad. Es así que el abordaje transversal de la ESI encuentra un punto de negociación intermedia en el cual la sexualidad o el género entra a la institución y/o a las asignaturas al menos una vez por año, pero sin necesariamente implicar todo el programa curricular. Se trata de un modo de apropiación de una de las herramientas políticas más estables de la gramática escolar que tuvo y tiene el objetivo de construir una identidad nacional. Estas efemérides también aportan a construir una ciudadanía sexual.

\section{Conclusiones}

Hasta aquí analicé la noción de transversalidad en dos sentidos. Por un lado, recorrí distintas enfoques y también limitaciones de las definiciones de transversalidad que atañen a la Educación Sexual Integral para fundamentar mi foco en la dimensión institucional y no solo curricular de la enseñanza. Por otro lado, reconstruí lo observado en tres años de trabajo de campo y en particular ordené tres modos en que el grupo ESI-Género de la Escuela P tradujo a la vida cotidiana escolar la propuesta de transversalización de la perspectiva de género que la normativa ESI promueve.

Dicha apropiación implicó un proceso de revisión de los saberes, los cuerpos y las voces tradicionalmente legítimos, una puesta en valor de la arena política como ámbito pedagógico; la autovalidación de los saberes producidos en la escuela por lxs mismxs docentes y por lxs jóvenes estudiantes, y de otras agencias no escolares con amplio protagonismo en la vida online. Se destacan las alianzas y tensiones inter e intrageneracionales y las estrategias colectivas que buscaron desbordar la organización tradicional de las voces, los tiempos y los espacios escolares, a la vez que la puesta en valor del papel que cumple la escuela como un espacio de encuentro privilegiado para ensayar nuevos modos de conocer, accionar y vincularse.

Dicho esto y para finalizar, quisiera dejar una reflexión sobre lo que llamo "riesgos y potencias de la transversalidad" en el caso de la ESI. El riesgo es la posible disolución o desdibujamiento de los aportes de la perspectiva de la ESI y de los feminismos en aquellas instituciones en las que ningún miembro de la comunidad "se hace cargo". Siendo que no se trata de una asignatura o un nombramiento, es usual que nadie asuma o se interese en promover acciones en torno a los materiales y enfoques que la normativa habilita, en particular en lo referido a los aportes de los feminismos, para revisar el currículum y la vida cotidiana escolar. La potencia, por otra parte, radica en la posibilidad de transformar los mecanismos por los cuales se establece un reconocimiento del poder de las alianzas trans/intergeneracionales y trans/interdisciplinares, 
históricamente marginalizados de los criterios de validación. El caso de la escuela analizada puede ser un puntapié para ahondar en qué sucede en instituciones donde existe una voluntad colectiva de implementar la ESI en tanto perspectiva y no solo la inclusión de temas a los ya abultados programas. Considero que es menester seguir ahondando en las características subjetivas, curriculares, institucionales y territoriales que condicionan el despliegue máximo de dichas voluntades. Mi propuesta de establecer diálogos entre la ESI, la etnografía escolar y las pedagogías/epistemologías feministas permitirá estudiar con mayor rigurosidad los procesos de jerarquización o desjerarquización de los cuerpos, roles y saberes que funcionan como ejes vertebradores de comunidades tan burocratizadas como las escolares. 


\section{Bibliografía}

" Aguilera, O. (2011). “Acontecimiento y acción colectiva juvenil. El antes, durante y después de la rebelión de los estudiantes secundarios chilenos en 2006”. Revista Propuesta Educativa, 35, pp. 11-26.

»Bach. A. M. (comp.) (2015). Para una didáctica con perspectiva de género. San Martín, Argentina: Miño y Dávila, Universidad Nacional de General San Martín.

»Castells, M. (2002). Transformación del trabajo y el empleo y Estado de Bienestar en la sociedad de la información. Gaceta Sindical.

"De Alba, A. (2015). Cultura y contornos sociales. Transversalidad en el currículum universitario. En De Alba, A. y Casimiro Lopes, A. (coords.), Diálogos curriculares entre México y Brasil (pp. 195-211), Ciudad de México: IISUE-UNAM.

»Dussel, I. y Southwell, M. (2009). Los rituales escolares: pasado y presente de una práctica colectiva. Revista El Monitor (21), pp. 26-29.

"Escolano Benito, A. E. (2000). Tiempos y espacios para la escuela: ensayos históricos (Vol. 1). Buenos Aires: Biblioteca Nueva.

» Fattore, N.(2007). Apuntes sobre la formaescolar "tradicional" ysus desplazamientos. En Baquero, R.; Dicker, G. y Frigerio, G., Las formas de lo escolar, Buenos Aires: Del Estante, pp. 13-33.

» Gago, V. (2019). La potencia feminista: o el deseo de cambiarlo todo. Madrid: Tinta Limón.

"Lopes Louro, G. (1999). Pedagogias da sexualidade. En Lopes L. (comp.), O corpo educado: pedagogias da sexualidade (pp. 7-34). Belo Horizonte, Brasil: Autêntica.

» Maher, F. y Thompson Tetreault, M. K. (1994). El aula feminista. Una mirada interna sobre cómo profesores y estudiantes están transformando la educación superior para una sociedad diversa. Nueva York: Basic Books.

"McIntosh, P. (1997). Interactive phases of curricular and personal re-vision with regard to race. En Adams J. y Welsch J. (ed.), Multicultural Prism: Voices from the Field. Volume 3, pp. 19-36.

》 Morgade, G. (coord.) (2011). Toda educación es sexual. Buenos Aires: La Crujía.

» Núñez, P. y Litichever, L. (2015). Sociabilidad en la escuela secundaria: experiencias, expectativas y demandas juveniles. En Núñez, P. y Litichever, L., Radiografías de la experiencia escolar. Ser joven(es) en la escuela (pp.17 a 38). Buenos Aires: Grupo Editor Universitario.

» Siede, I. (1998). El aporte de las ciencias sociales a la educación en la paz y los derechos humanos. Revista de Teoría y Didáctica de las Ciencias Sociales, 3 (3) 164-194.

"Subirats, M. y Brullet, C. (1988). Rosa y Azul. La transmisión de los géneros en la escuela mixta. Madrid: Instituto de la Mujer.

» Terigi, F. (2008). Los cambios en el formato de la escuela secundaria: por qué son necesarios, por qué son tan difíciles. Propuesta Educativa, 29, año 17, pp. 63-72.

" Terigi, F. (2013). Exploración de una idea. En torno a los saberes sobre lo escolar. En Baquero, R., Diker, G. y Frigerio G. (comp.), Las formas de lo escolar (p. 99-117). Buenos Aires: Del Estante. 
»Willis P. (1983). Aprendiendo a trabajar. Madrid: Akal.

\section{Catalina González del Cerro}

Doctora en Educación y Profesora de nivel medio y superior en Ciencias Antropológicas por la Universidad de Buenos Aires. Becaria postdoctoral del Consejo Nacional de Investigaciones Científicas y Técnicas. catalinag@gmail.com 